\title{
Migración, comercio y guerra: las relaciones entre Japón, México y Estados Unidos antes de Pearl Harbor
}

DOI: $10.32870 /$ mycp.v3i6.419

Sergio Hernández Galindo ${ }^{1}$

\section{Resumen}

Cuando la Guerra del Pacífico inició en diciembre de 1941 entre Estados Unidos y Japón, los enfrentamientos entre ambos países ya tenían un largo tiempo de haberse iniciado. Las disputas comerciales y en torno a la migración japonesa hacia el continente americano ya tenían un largo proceso de maduración. El escenario de dichas disputas se había concentrado en México; el interés de ambas potencias por una serie de materias primas como el petróleo que brotaba en grandes cantidades en ese país, había sido motivo de intensas presiones sobre el Gobierno mexicano. La etapa de cooperación que había dado lugar a acuerdos comerciales y de cooperación económica donde se incluía a la propia migración a principios de siglo quedó en el olvido. El desarrollo de Estados Unidos y Japón como grandes potencias fue el motivo principal que llevó finalmente a la guerra total.

Palabras clave: Japón, México, Estados Unidos, comercio, migrantes japoneses, Guerra del Pacífico.

Artículo recibido el 26 de mayo de 2013 y dictaminado el 4 de junio de 2013.

1. Dirección de Estudios Históricos, INAH. e-mail: sergioherg@prodigy.net.mx. 


\section{Abstract. Inmigration, Commerce and War: Relations between Japan, Mexico and the United States before Pearl Harbor}

When the Pacific war down began in December 1941 between United States and Japan, the clashes between the two countries already had a long time to have been initiated. The trade and disputes around the Japanese migration to the Americas already had a long process of maturation. The scene of these disputes had concentrated in Mexico; the interest of both powers by a series of raw materials as oil emanating in large quantities in the country, had been intense pressure on the Mexican Government. The stage of cooperation which had given rise to trade agreements and economic cooperation which included Japanese migration at the beginning of century was forgotten. The development of US and Japan as major powers was the main reason that eventually led to total war.

Keywords: Japan, Mexico, United States, trade, Japanese migrants, Pacific War.

\section{Introducción}

El ataque japonés a la base naval de Pearl Harbor el 7 de diciembre de 1941 dio inicio a las hostilidades militares entre Estados Unidos y Japón. La Guerra del Pacífico, como es conocida, llevó a un enfrentamiento brutal entre ambos países cuyo costo en vidas ascendió a millones de personas, tanto civiles como militares, ${ }^{2}$ y terminó con el lanzamiento de dos bombas atómicas el mes de agosto de 1945 a las ciudades de Hiroshima y Nagasaki.

A pesar de que México no participó realmente en esta guerra, no significó que fuera ajeno a la misma. En el plano militar el Ejército y la Armada se transformaron y modernizaron para apoyar los esfuerzos de guerra de Estados Unidos, aunque en el campo de batalla tuvo una participación minúscula mediante el envío de un pequeño escuadrón de aviación al Pacífico a dos meses de la derrota de Japón. México igualmente fue parte de un escenario de disputa entre las potencias por el control de las materias primas necesarias para la guerra, por lo que se vio obligado a responder a los requerimientos

2. El total de japoneses muertos ascendió a cerca de dos millones 700 mil, siendo cerca de un millón civiles. El número de militares estadounidenses muertos sobrepasó los 100 mil (Dower, 1986: 297300). 
y presiones de los poderes dominantes. El país obtuvo ventajas de la guerra pero igualmente enfrentó fuertes retos que los desequilibrios mundiales en el plano económico y político le demandaron. La sociedad en su conjunto incluso no estuvo ajena a estas transformaciones; sus fobias y filias sobre antiguos enemigos o aliados se transformaron, buscando en ellos virtudes o defectos que antes no poseían ante el desgarramiento de las pugnas internacionales. ${ }^{3}$

Aunque el enfrentamiento militar entre Estados Unidos y Japón comenzó a finales de 1941, años atrás se enfrascaron en una gran batalla con el propósito de obtener recursos y materias primas para sus economías sin haber disparado un solo tiro. El periodo de guerra por tanto al que me referiré en este trabajo será el anterior justamente a Pearl Harbor, pues como escribió Thomas Hobbes, la guerra es más que la batalla o la lucha en sí misma, es "el espacio de tiempo en el que reina la voluntad de resolver las diferencias por medio de la batalla". ${ }^{4}$ México fue el escenario de esta disputa entre ambas potencias, por lo que aun antes de romper sus relaciones con Japón, inmediatamente después del ataque naval a la base estadounidense, ese país ya se encontraba inmerso en el conflicto. En este sentido las relaciones comerciales, diplomáticas y en torno a la migración japonesa de manera especial, que mantenía México con las grandes potencias se trastornaron rápidamente años antes del 7 de diciembre de 1941.

Si para el economista inglés Adam Smith el mercado se convierte en la "mano invisible" capaz de regular las relaciones económicas y sociales, en este ensayo me tendré que referir a "la mano negra"5 que utilizaron Japón y Estados Unidos en su trato con México con objeto de lograr ventajas que les permitieran afianzar sus intereses en ese país. En efecto, como mostraré, ambos países usaron de manera extensa a lo largo de las décadas previas al estallido de la guerra, mecanismos extraeconómicos, legales e ilegales, para beneficiarse de sus relaciones con México, obstruyendo de manera sistemática a sus competidores. Más aún, lejos de atenerse a la mano invisible y de autorregulación del mercado, las embajadas de esos países mediante sus agregados militares, navales y comerciales, junto con empresarios, actuaron de manera activa y decidida para orientar las actividades económicas que

3. Véase en este aspecto el sugerente trabajo de Rankin (2009).

4. Citado por Hobsbawm (2007: 2).

5. En México se usa la expresión "mano negra" cuando existe la intervención indebida de alguien que no tiene derecho de participar en un juego o asunto. Es una forma tramposa de ganar en un negocio de manera oculta para beneficiarse de algo y así obtener provechos personales o de grupo. 
posicionaran a sus países de la mejor manera en su relación con el Gobierno mexicano, asumiendo un papel en muchos casos de saboteadores de posibles acuerdos del Gobierno mexicano con sus adversarios. El petróleo mexicano de manera especial fue la materia prima que adquirió una gran relevancia y que

El petróleo mexicano de manera especial fue la materia prima que adquirió una gran relevancia y que fue parte sustancial de los diferendos entre Japón y Estados Unidos fue parte sustancial de los diferendos entre Japón y Estados Unidos. ${ }^{6}$

El análisis en este ensayo hace referencia también a la participación de los migrantes japoneses en el continente americano. Los inmigrantes en muchas ocasiones, sin quererlo o saberlo, fueron parte sustancial de la serie de enfrentamientos entre Estados Unidos y Japón. Las comunidades de japoneses en todo el continente se convirtieron en un principio en la mano de obra que requirieron muchos países del continente para apoyar su crecimiento económico, pero al acercarse la guerra se les consideró como parte de los activos del Ejército Imperial japonés, por lo que se les persiguió y concentró en campos de concentración, aun a pesar de que sus hijos ya no eran ciudadanos japoneses. Las comunidades de inmigrantes, al estar arraigados fuertemente en diversos países, fueron involucrados en la disputa de los intereses económicos y estratégicos que se pusieron en juego.

\section{Los primeros contactos con Japón}

La apertura forzada de los puertos y el comercio de Japón a mediados del siglo XIX transformó de manera acelerada al país insular. Esta apertura obligada por Estados Unidos mediante el desembarco de los llamados "barcos negros" en la bahía de lo que hoy es Tokio en el año de 1853, abrió una nueva etapa en la conformación de las relaciones entre las grandes potencias y su entorno con los países de la periferia. Como parte de este nuevo entorno podemos entender la serie de tratados que Japón entabló con diversos países

6. El petróleo no fue la única materia estratégica en disputa, pues existieron otras como el mercurio y el espato de flúor. La pesca también constituyó un vértice de enfrentamiento que no abordo en este trabajo. 
de Latinoamérica y en particular con México, pues las bases del mismo se sustentaron sobre bases de equidad que servirían como ejemplo para echar atrás aquéllos firmados con las grandes potencias que le impusieron a Japón condiciones de extraterritorialidad. Los primeros contactos entre Japón y México que permitieron la firma de ese convenio se dieron a partir de un acontecimiento planetario: el tránsito del planeta Venus por el disco solar. El geógrafo Francisco Díaz Covarrubias fue quien encabezó la delegación mexicana, por lo que se dirigió a la ciudad de Yokohama en 1874, donde instaló un campamento para observar tal fenómeno. A su regreso a México, Díaz Covarrubias presentó un informe del viaje al Gobierno mexicano en el que no sólo reportó las incidencias de la misión, sino que detalló sus impresiones de Japón. En el reporte, Díaz Covarrubias (2008: 222) no dejó de mostrar su admiración por los japoneses, describiéndolos "siempre afables, corteses, valientes, pundonorosos y muy dóciles de aceptar todo género de cultura”, por lo que recomendó además abrir la migración japonesa a México (en contraste con la migración de China), pues a sus ojos ofrecería al país un "gran número de jornaleros baratos, activos e inteligentes".

Los deseos de Díaz Covarrubias finalmente se tradujeron años después en una serie de pláticas entre los gobiernos de ambas naciones con el propósito de entablar relaciones formales. En 1881, durante el gobierno del presidente Manuel González, se recomendó que dado el desarrollo de las vías férreas que se estaban construyendo hacia el Pacífico, "ha llegado el momento de que se establezcan relaciones comerciales con China y Japón" (Ota Mishima, 1976: 15). Esta consideración se basó en el hecho de que la plata mexicana era muy valorada en los mercados orientales, a diferencia de lo que sucedía en los europeos. Además se pensó que los productos orientales que se importaban vía países europeos, podrían ser transportados por una compañía de vapores que se había constituido en 1884, la Compañía de Vapores del Pacífico. Aunque esta compañía no se llegó a constituir finalmente pues el establecimiento de relaciones entre México y Japón se retrasó cuatro años después, la misión mexicana que encabezó en Washington el canciller Matías Romero concluyó con la firma del Tratado de Amistad, Comercio y Navegación en 1888. El tratado permitió no sólo la apertura comercial, sino el libre tránsito de ciudadanos de ambos países y la contratación sin restricción alguna de trabajadores y de migrantes libres.

Estados Unidos en ese entonces ya había entablado acuerdos en el campo migratorio con Japón; la contratación de trabajadores japoneses fue bien 
vista durante las primeras décadas en ese país. De hecho la migración había comenzado años atrás en Hawai, territorio que posteriormente se anexaría Estados Unidos. En 1900 residían en esa isla más de 60 mil migrantes y en toda la costa oeste, mayoritariamente en California, radicaban cerca de 20 mil. ${ }^{7}$

El número total de japoneses que se dirigieron a todo el continente americano desde 1868 hasta antes de estallar la guerra ascendió a más de 700 mil personas. ${ }^{8}$ A México se trasladaron en ese periodo más de 14 mil migrantes desde 1897, año en que ingresaron los primeros 36 migrantes a la zona del Soconusco, en Chiapas, donde levantaron una finca cafetalera. ${ }^{9}$ Sin embargo, al estallar la guerra del Pacífico, el total de japoneses que radicaban en todo el continente americano llegó a cerca de 310 mil personas.

El año 1910 marcó un momento importante para la relación entre México y Japón. El primer centenario de la independencia de México fue motivo para realizar un gran festejo por parte del Gobierno mexicano, que involucró activamente a las misiones diplomáticas acreditadas. Los países que enviaron un ministro plenipotenciario sólo fueron siete, entre ellos Estados Unidos y Japón (García, 1911). ${ }^{10}$

Pero así como existía esta atracción mutua entre Japón y México, las relaciones que entabló el país oriental con Estados Unidos a principios del siglo $\mathrm{xx}$ fueron cordiales y complementariamente benéficas para ambas naciones. $\mathrm{El}$ presidente estadounidense Theodore Roosevelt en 1904 simpatizó con la posición de Japón en la guerra contra Rusia, y al igual que Franklin D. Roosevelt, en esos entonces aún muy joven, mantuvo una fuerte admiración y cariño por Japón y su pueblo. ${ }^{11}$ Sin embargo, la visión del Gobierno estadounidense sobre Japón fue cambiando a lo largo de los años y pasó de una actitud paternal y protectora a mediados del siglo XIX, cuando lo obligaron por la fuerza a abrir sus fronteras, a la de desconfianza creciente que se inició en la primera década del siglo Xx, cuando Japón derrotó militarmente a Rusia en 1905, y el poder de su flota naval creció

7. Datos tomados de U. S. Census, 1900-1990, en Niiya (2001).

8. De acuerdo con datos del Ministerio de Asuntos Exteriores de Japón (1971: 137-147).

9. Esta historia es narrada por Ueno (s/f) en formato de manga japonesa. El estudio detallado de la migración japonesa a México se encuentra en Ota Mishima (1988).

10. El presidente Porfirio Díaz igualmente recibió la orden del gran crisantemo como muestra de la importancia que Japón otorgaba a las relaciones con México.

11. Los lazos personales que mantuvieron los Roosevelt con japoneses fueron constantes a lo largo de varias décadas, incluso aun cuando Franklin se convirtió en presidente en la década de los treinta hasta el momento en que estalló la guerra (Robinson, 2001: 10 y 11). 
exponencialmente en la región del Pacífico, por lo que se empezó a convertir en un problema nodal de la política exterior estadounidense de gran potencia. ${ }^{12}$

La cordial relación diplomática entre Japón y México así como el crecimiento económico que experimentaron ambos países a finales del siglo XIX no se expresó en incrementos sustanciales de sus flujos comerciales. El intercambio comercial entre ambos nunca sobrepasó 3\% de su comercio exterior total, a diferencia del que mantuvieron con las grandes potencias económicas que les demandaron de manera creciente materias primas, productos semielaborados y, en el caso de Japón, de consumo final. Para ambos países los niveles de comercio se tradujeron en una creciente dependencia comercial con las grandes economías, de manera particular con EU (véase cuadro 1). Sin embargo existieron diferencias notables en el comportamiento de ambos, pues mientras México se orientó a la exportación de materias primas, Japón lo hizo muy rápidamente en la de productos manufacturados, como los textiles. Respecto a las importaciones, Japón mantuvo una dependencia asfixiante con Estados Unidos en el rubro de algunas materias primas como el petróleo, a diferencia del caso mexicano, cuyo embargo por parte de Eu fue uno de los detonadores del ataque a Pearl Harbor. Además, la escasez de este tipo de materias en el archipiélago japonés lo obligó a mantener una relación estructuralmente diferente con los grandes poderes económicos y en buscar fuentes alternas de las mismas que le permitieran sostener su crecimiento industrial acelerado, hecho que lo llevó a desarrollar una política imperialista muy agresiva con los países vecinos.

12. El almirante estadounidense Alfred T. Mahan, mediante su libro The influence of Sea Power Upon History, influyó en el joven Roosevelt y en toda esa generación de políticos de inicios del siglo xx. La consideración geoestratégica de Mahan en el sentido de que ninguna potencia puede sobrevivir si no posee el dominio sobre los mares se convirtió en parte fundamental de la política exterior estadounidense. Incluso Mahan advirtió que Estados Unidos y Japón inevitablemente se enfrentarían por las posiciones que iban ocupando en el Pacífico. Más aún, la obra de Mahan se tradujo al japonés y fue libro obligado de texto para los oficiales navales japoneses (Neumann, 1953). 
Cuadro 1

Porcentaje del comercio de México y Japón con Estados Unidos ${ }^{13}$

\begin{tabular}{lcccc}
\hline & \multicolumn{2}{c}{ Importaciones } & \multicolumn{2}{c}{ Exportaciones } \\
\cline { 2 - 5 } Periodo & México & Japón & México & Japón \\
\hline $1890-94$ & 75 & 8 & 74 & 37 \\
$1895-99$ & 51 & 12 & 77 & 30 \\
$1900-04$ & 55 & 16 & 75 & 28 \\
$1905-09$ & 60 & 14 & 72 & 29 \\
\hline
\end{tabular}

Fuente: elaboración propia.

Es importante destacar en este sentido cómo las industrias más dinámicas que se ligaban a la economía internacional, en el caso de México correspondieron al sector minero con más de $60 \%$ del total de las exportaciones y que estaban en manos de extranjeros, mientras que para Japón $42 \%$ del valor total se ubicaba en los sectores ligados a las industrias tradicionales productoras de tela, seda cruda, té, trenzados de paja y porcelana, además de que otro $20 \%$ del total de las exportaciones eran de las industrias de hilado y tejido de algodón (Hernández, 2003a). Japón pudo ligar por tanto la apertura forzada de su economía a sus sectores tradicionales que le permitieron no sólo modernizarlos, sino que sirvieran de punta de lanza para la obtención de divisas necesarias para obtener los productos y bienes de capital que requirió su primera fase industrializadora.

\section{Migración y expansión hacia afuera}

Las oleadas de migrantes japoneses comenzaron a salir de manera creciente de Japón en las últimas décadas del siglo XIX. A pesar de la acelerada industrialización que experimentaba y del crecimiento de las grandes ciudades, la economía nipona no fue capaz de retener los flujos de trabajadores que el sector agrícola desechaba. Este proceso de expulsión de mano de obra tuvo otra característica importante, pues mediante las profundas transformaciones políticas que con gran celeridad se impulsaron durante el régimen de Meiji (1868-1912) ${ }^{14}$ se pusieron

13. Datos elaborados con base en datos para México del Instituto Nacional de Estadística, Geografía e Informática, y para Japón de Nihon Kindaishi Jiten, Enciclopedia de la historia moderna de Japón.

14. Una de las formas de dividir la historia japonesa es a partir del periodo de reinado de los emperadores. Las eras que siguieron a Meiji, denominadas Taisho (1912-1926) y Showa (19261989), con el ascenso al trono del emperador Hirohito, representan en conjunto el auge y caída 
en marcha una serie de medidas migratorias coordinadas por el propio Estado que lanzaron al exterior a cientos de miles de trabajadores. A partir de 1868, Japón se enfrascó en una carrera con el propósito de equipararse con las grandes potencias económicas, al grado de que fue el único país cuya industrialización per cápita creció en casi 10 veces de 1880 a 1938 y le permitió acercarse al nivel de las grandes economías (cuadro 2). Sin embargo, en una época de fuertes disputas imperiales, el crecimiento económico japonés estuvo asociado íntimamente al expansionismo militarista, a tal grado que no podía existir uno sin el otro como lo promovieron los dirigentes de Meiji mediante el binomio fukoku-kyohei, país rico-ejército poderoso (Nakamura, 1980: 57-69). A inicios del siglo xx, Japón se fue erigiendo en un poder militar en la región, llegando a ocupar varios países y a convertirse en el único poder no occidental en Asia.

\section{Cuadro 2}

Niveles de industrialización per cápita 1880-1938 ${ }^{15}$

(Base 100 GB 1900)

\begin{tabular}{lrrrrr}
\hline & 1880 & 1900 & 1913 & 1928 & 1938 \\
\hline 1. Estados Unidos & 38 & 69 & 126 & 182 & 167 \\
2. Gran Bretaña & 87 & 100 & 115 & 122 & 157 \\
3. Alemania & 25 & 52 & 85 & 128 & 144 \\
4. Japón & 9 & 12 & 20 & 30 & 88 \\
5. Francia & 28 & 39 & 59 & 82 & 73 \\
6 Rusia & 10 & 15 & 20 & 20 & 38 \\
\hline
\end{tabular}

Fuente: elaboración propia.

La dinámica que le impusieron las potencias occidentales al crecimiento de la economía-mundo capitalista, en México como en Japón no sólo impulsó un acelerado crecimiento industrial y comercial de estos países, sino que orilló a que centenas de miles de trabajadores japoneses traspasaran las fronteras nacionales en busca de un empleo en diversos países del continente americano

de la etapa imperialista de Japón. Usaré en adelante la palabra japonesa Tenno para designar al emperador, por el carácter sagrado que se le dio a su autoridad a partir de la restauración Meiji de 1868. Esta característica fue de gran importancia para los eventos que describo más adelante en este trabajo; consúltese desde esta perspectiva de estudio, el sistema del Tenno en el trabajo de Irokawa (1985: 245-311).

15. Cuadro elaborado con base en datos de Bairoch (1982). 
y como colonizadores en países de Asia. La integración y relación que se empezó a entablar entre los países del continente americano con Japón abrió un espacio muy intenso en el flujo de mercancías y hombres a lo largo y ancho de la Cuenca del Pacífico, pero a su vez desató una fuerte competencia por el control de esta región entre las nacientes potencias en que se erigieron Estados Unidos y Japón.

\section{La política estadounidense de vigilancia sobre el "peligro japonés" en el continente}

La relevancia que la comunidad japonesa fue adquiriendo en todo el continente, especialmente en la costa oeste estadounidense desde principios del siglo $\mathrm{xx}$, motivó no sólo una campaña racista antijaponesa por parte de la población blanca, sino el interés y la preocupación en los altos niveles del Gobierno estadounidense. Durante las primeras tres décadas de ese siglo, la comunidad japonesa fue adquiriendo una importancia estratégica para la política estadounidense debido a dos factores: uno debido al incremento numérico de los migrantes y, en segundo lugar, por su creciente influencia en la economía y la sociedad californiana. La población japonesa en la región fue evolucionando de ser una de agricultores, obreros y pescadores pobres, a otra de propietarios agrícolas, comerciantes y pescadores destacados a lo largo de una extensa zona del Pacífico que abarcó toda la costa de California en Estados Unidos y el norte de la península de Baja California en México. ${ }^{16}$

Los migrantes japoneses se habían ido convirtiendo en propietarios o arrendatarios de parcelas de cultivo que explotaban eficientemente, produciendo poco a poco un gran porcentaje de los vegetales que se consumían en California ${ }^{17}$ y del algodón que se exportaba desde la parte mexicana en la región de Mexicali y de Sonora. Además explotaban la extensa y rica zona pesquera que se ubicaba a lo largo de la costa del Pacífico (tanto en su porción mexicana como estadounidense) y que encontraba, en los puertos de San Diego y San Pedro en Los Ángeles, su puerta de entrada a un enorme mercado en expansión. Igualmente la serie de pequeños comercios e industrias que empezaron a fundar, después de años

16. En 1905 existía ya un fuerte movimiento antijaponés por parte de amplios sectores que consideraban fundamental "mantener una California blanca" (Daniels, 1977: 46-64). El presidente Theodore Roosevelt, cuyo periodo en el cargo abarcó del año de 1901 a 1909, comenzó a considerar a ese país como un fuerte rival en la disputa por el poder mundial (Robinson, 2001: 14).

17. En California en 1900 existían 37 granjas de propietarios japoneses con una extensión total de cinco mil acres, pero para 1910 poseían 1,816 familias cerca de 100 mil acres (Ichioka, 1980: 150). 
de esfuerzo y ahorro familiar motivados por un fuerte impulso de regresar enriquecidos a su patria, fueron las actividades que les permitieron consolidarse económicamente y mantener un fuerte arraigo en los lugares donde se establecieron. Esta transformación en las condiciones socioeconómicas de los migrantes no se puede explicar sin la enorme capacidad de desarrollar una simbiosis entre la cultura del emigrante y la de la población receptora. ${ }^{18}$

Los primeros planes estadounidenses para vigilar a la comunidad japonesa y para limitar su número e influencia se empezaron a diseñar en el momento en que el país oriental se fue conformando como gran potencia en Asia, hecho que quedó de manifiesto cuando derrotó militarmente a la Rusia zarista en 1905 y con ello su influencia en China y en el noreste de Asia aumentó de manera paulatina. A partir de entonces, Estados Unidos consideró a Japón como un rival militar y a la migración en todo el continente como un serio "problema"; un nuevo "peligro amarillo" a partir de dos elementos que se fueron entrelazando: uno, por la propia penetración migratoria en Estados Unidos y Latinoamérica y su creciente poder económico y social; otro por el carácter expansionista de la política japonesa en Asia y su interés creciente en el continente americano. En San Francisco, California, se presentaron los primeros choques raciales contra los japoneses por motivo de la segregación escolar de que fueron objeto sus hijos a partir de 1906 (LaFeber, 1997: 87-92). El número creciente de japoneses en California y su arraigo inquietaron al Gobierno estadounidense y a la población blanca más racista y xenófoba. A partir de ese entonces se desató una campaña antijaponesa en la prensa que divulgaba abiertamente que su crecimiento representaba una amenaza de invasión de esa naciente potencia a Estados Unidos. Esta preocupación se fue generalizando en amplios sectores de la población en California, al grado que un ciudadano estadounidense envió una carta al Departamento de Guerra a principios de 1907 advirtiendo de manera gráfica, mediante un mapa (véase mapa 1), del peligro que corría su país si no se detenía a la migración de origen japonés y si no se enfrentaba el poderío militar nipón. ${ }^{19}$

18. Un ejemplo de la importancia de los migrantes en México se puede ver mediante el estudio de caso de la familia Kasuga (Hernández, 2003b). Respecto a la importancia de la comunidad de pescadores en Ensenada, consúltese a Nishikawa (2002). La importancia creciente de los primeros migrantes japoneses y su organización en general en EU puede verse en Ichioka (1980), especialmente capítulos IV y V. La comunidad de pescadores en ese país es estudiada por Estes (1977).

19. National Archives and Records Administration (NARA), College Park, Maryland. Carta del Sr. Lyman M. Wood al Secretario de Guerra. Record Group 165. Records of the War Department, Military Intelligence Division (MID) 1766-14, febrero de 1907. A partir de aquí, NARA. R. G. 165. 


\section{Mapa 1}

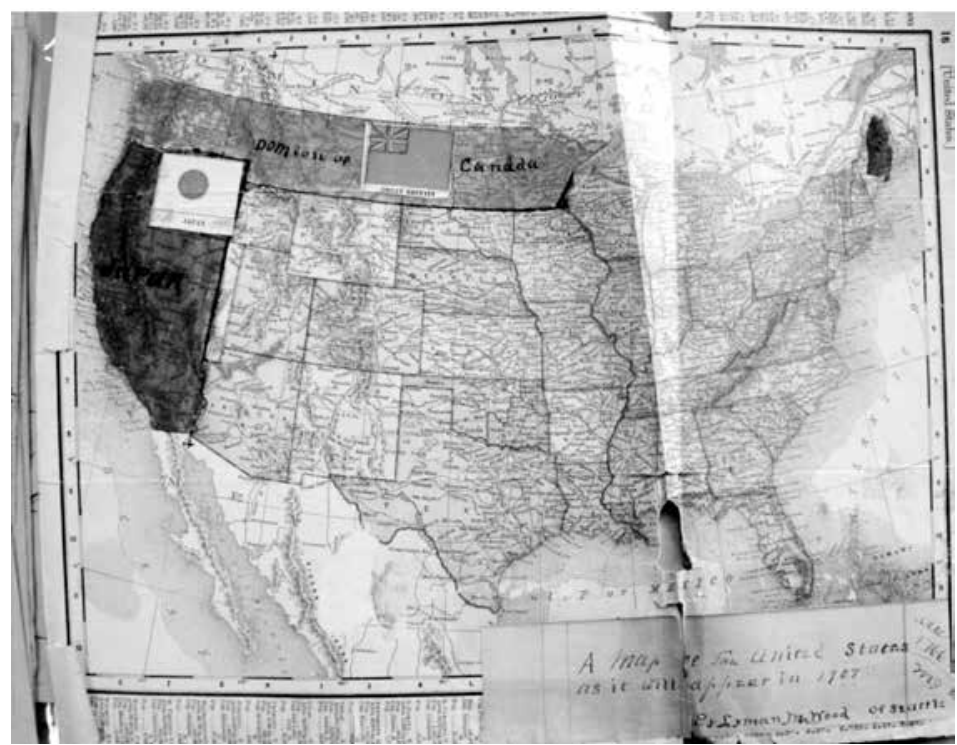

La preocupación que guardaban el Gobierno estadounidense y los sectores xenofóbicos de California sobre la migración japonesa se hizo extensiva a los migrantes que residían en México. Se vinculó a los trabajadores japoneses en una supuesta invasión hacia Estados Unidos desde la frontera mexicana. En una carta dirigida al secretario de Estado estadounidense en ese mismo año, se le informó que en el estado de Coahuila, fronterizo con Texas, "muchos de los trabajadores japoneses son en realidad espías" y que incluso un oficial japonés, junto con su hijo, habían arribado al puerto de Mazatlán con la finalidad de realizar un conjunto de mapas que sirvieran a las fuerzas militares japonesas para una "posible invasión a Estados Unidos". ${ }^{20}$ La prensa estadounidense igualmente se hizo eco de esos rumores; en una nota se informó que detrás de los mineros pobres japoneses que habían emigrado a México, se escondían en realidad espías enviados por el

20. Carta de William Ingran, miembro de la Asociación Norteamericana de la Biblia, al secretario de Estado Elihoo Root. La información la recibe Ingran de un miembro de esa asociación en México. NARA. R. G. 165. MiD, 1766-26, septiembre de 1907. 
Gobierno japonés, lo que dio motivo para que los servicios de inteligencia militar estadounidenses comenzaran a investigar a la comunidad japonesa en México. ${ }^{21}$

Toda esta tensión que se vivía en Estados Unidos respecto a los migrantes, intentó ser resuelta mediante un llamado "acuerdo de caballeros" realizado en 1907 entre los gobiernos de Japón y Estados Unidos con objeto de impedir, de manera concertada, la salida de japoneses hacia territorio estadounidense. Esta situación afectó también a la migración que se dirigía a Canadá y México, hecho que a su vez orilló a que las oleadas de migrantes fluyeran de manera más intensa hacia Sudamérica. Con todo y la existencia de este acuerdo, la migración hacia Estados Unidos avanzó por senderos ilegales al utilizar los braceros japoneses a México como ruta de acceso.

La Embajada alemana en México también informaba sobre los migrantes japoneses. En 1907 mandó un reporte a su cancillería informando que como consecuencia del "acuerdo de caballeros" entre Estados Unidos y Japón para reducir el número de japoneses que emigraran a ese país, ingresaron a México miles de braceros que entrarían ilegalmente a Estos Unidos. De acuerdo con estos reportes, sólo en el verano de ese año llegaron a México más de 12 mil japoneses con ese propósito, lo que a todas luces resultaba altamente exagerado. La inteligencia germana a pesar de estas dudas, sostenía que México no sólo era un puente para que ingresaran japoneses a Estados Unidos, sino que era el lugar para que las fuerzas armadas japonesas prepararan y dirigieran una invasión que era "inminente". ${ }^{22}$ Sin saberlo, los inmigrantes japoneses se habían convertido en esos reportes en la fuerza de choque de esa invasión, ya que se reportó que se encontraban incluso armados. Más aún, se informó que cinco mil japoneses en el estado de Chihuahua y tres mil en el estado de Jalisco estaban listos para recibir las armas. Aunque la inteligencia alemana creía exagerados este tipo de rumores, sí consideraba que era posible que Japón, en caso de guerra con Estados Unidos, "formara un gran contingente armado con sus reservistas en México"23 y utilizara territorio mexicano como "base de operaciones para un ataque contra California". ${ }^{24}$ Fue tal la paranoia que la inteligencia alemana tenía sobre la fuerza de los migrantes japoneses, que en una carta escrita por el káiser Guillermo II al zar Nicolás II aseguró que en caso de guerra entre Japón y Estados Unidos, los

21. NARA. R. G. 165. Mid 1766-26, abril de 1907.

22. Informe del canciller alemán Wangenheim a Bülow del 25 de mayo de 1907. Citado por Katz (1982: 90).

23. Wangenheim al cónsul alemán en Guadalajara, 8 de abril de 1907 (Katz, 1982: 90).

24. Wangenheim a Bülow, 15 de julio de 1907 (Katz, 1982: 91). 
japoneses en México tendrían la capacidad de tomar el Canal de Panamá y cortar esa comunicación estratégica. ${ }^{25}$

Al estallar la Revolución Mexicana en noviembre de 1910, informes de la inteligencia militar estadounidense no descartaban que el movimiento armado tuviera relación con intereses promovidos por diplomáticos japoneses. Según esos informes, el Gobierno japonés tenía el propósito de causar conflictos entre México y Estados Unidos, o incluso una guerra, para de esta manera debilitar la estrategia y las posiciones estadounidenses en Oriente. ${ }^{26}$ Otro rumor que se mencionó fue el interés de miembros de las fuerzas navales japonesas para adquirir una isla en el Caribe mexicano denominada Isla Mujeres, rumor al que finalmente no dieron importancia alguna los militares estadounidenses, pues desde su punto de vista la ubicación de tal isla carecía de importancia estratégica. ${ }^{27}$

El número creciente de emigrantes en todo el continente comenzó a inquietar al Gobierno estadounidense. El Departamento de Guerra envió a sus embajadas en Latinoamérica un memorándum solicitándoles información precisa sobre la cantidad de japoneses y las actividades que realizaban. ${ }^{28}$ En México, la solicitud de tal información coincidió con la visita oficial de una delegación naval japonesa, el escuadrón naval de entrenamiento Asami y Kasagi (véase foto 1). El agregado militar de la embajada de Estados Unidos fue el encargado de trasladarse al puerto de Salina Cruz, Oaxaca, para reportar las actividades del escuadrón. El reporte destacó el excelente recibimiento que tuvo la delegación naval y señaló de manera especial la ceremonia de reconocimiento que hicieron los japoneses al valor de los jóvenes militares mexicanos que murieron durante la invasión estadounidense a México en el año de 1847 en el Castillo de Chapultepec. ${ }^{29}$

25. Carta del káiser Guillermo II al zar Nicolás II, 28 de diciembre de 1907 (Katz, 1982: 93).

26. Reporte militar de inteligencia de Filipinas a Washington. NARA. R. G. 165. MID, 1766-141, noviembre 23 de 1910.

27. Oficina del agregado militar de la embajada estadounidense en México. NARA, R. G. 165. Mid 1766150, febrero 13 de 1911. Isla Mujeres es uno de los destinos turísticos más importantes de México actualmente, ubicada enfrente de Cancún.

28. NARA. R. G. 165. Mid 1766-141. Enero 3 de 1911.

29. Ídem. 


\section{Foto $1^{30}$}

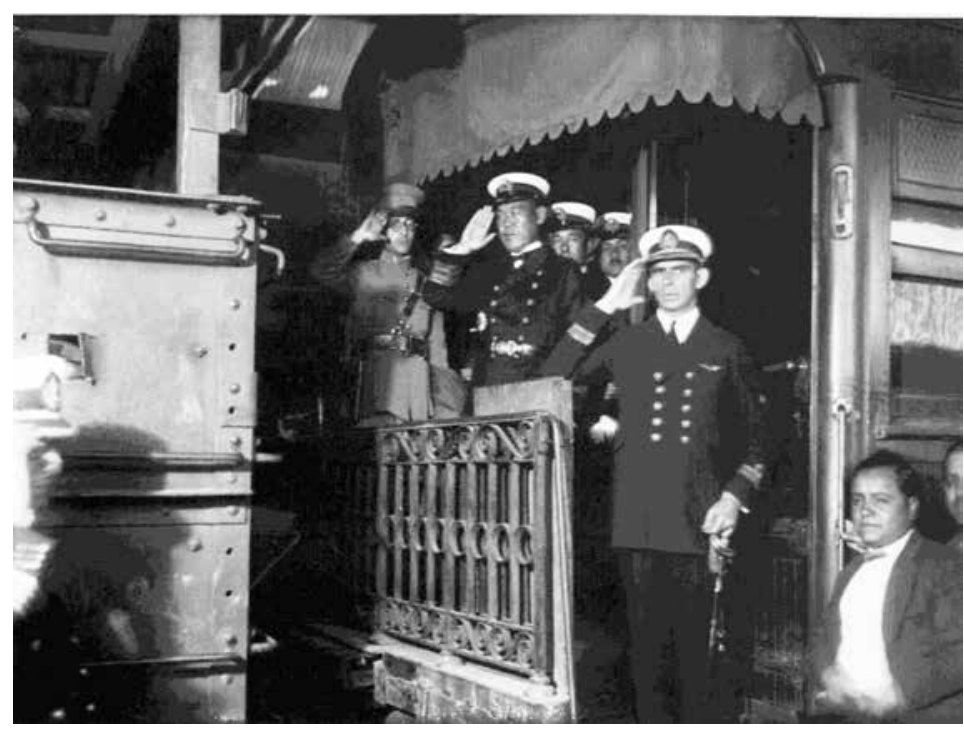

Otro hecho que se sumó a este ambiente de disputa entre Japón y Estados Unidos, y que involucró a México, fue el referente a la supuesta compra por la Marina Imperial Japonesa de la Bahía Magdalena, situada en las costas de la península de Baja California. La relación estrecha que se le atribuía al general Díaz con Japón causó tal revuelo en los círculos políticos estadounidenses, que consideraron de manera seria tal compra. La fuente de dichos rumores provenía de la prensa estadounidense, y fue tal el escándalo que el incidente escaló a tal magnitud, al extremo de ser considerado seriamente por el Senado estadounidense y por el propio presidente William Taft (1909-1913). Bahía Magdalena era un sitio estratégico para los estrategas navales estadounidenses como punto de punta de playa de una invasión a tierra firme; por otro lado, la bahía era utilizada regularmente para prácticas navales estadounidenses desde finales del siglo XIX, por lo que una concesión y el interés para ser vendida a Japón causaron una enorme preocupación en Washington. La colonización de la zona para establecer una zona pesquera, en efecto fue otro hecho considerado seriamente por inversionistas no sólo japoneses sino estadounidenses que empezaron a desarrollar sus actividades de exploración y explotación aun

30. Archivo General de la Nación. Fondo Díaz, Delgado y García (AGN-DDG) 18/21. 
después de que la presidencia de Díaz llegara a su fin en 1911, hasta el inicio de la Guerra del Pacífico. ${ }^{31}$

\section{Migrantes, comercio y seguridad continental}

Al finalizar la Primera Guerra Mundial, las diferencias entre Japón y Estados Unidos se fueron agravando ante la nueva configuración mundial de las grandes potencias. En relación con la situación de la migración, un primer conflicto se debió a la decisión de cerrar de manera definitiva el ingreso de trabajadores japoneses a Estados Unidos en el año 1924 mediante la promulgación una nueva Acta de Inmigración aprobada por el Congreso. El acta no sólo imposibilitó la inmigración japonesa, sino que fue fundamentada por el Congreso bajo una base eugenista, de mejoramiento racial, como elemento central para impedir el ingreso de "amarillos". Esta aprobación condujo las relaciones nipo-americanas a uno de sus puntos más bajos hasta antes del agravamiento que llevó a la guerra en 1941. En California la promulgación del acta excluyente, en lugar de atenuar el movimiento antijaponés, exaltó los sentimientos xenofóbicos de los sectores sociales racistas, que consideraron que esa acción pondría fin a la "invasión japonesa".

Ante el agresivo expansionismo de Japón y Alemania al inicio de la década de 1930 y un crecimiento inusitado del intercambio comercial de Japón con América Latina, el Gobierno estadounidense fue elaborando una estrategia mucho más amplia y profunda que puso no sólo atención a la defensa de su propio territorio, sino a la seguridad más allá de sus fronteras. Esta estrategia dio sus primeros pasos al involucrar de manera paulatina a todos los gobiernos latinoamericanos en la defensa de todo el continente, que se fue discutiendo en las Conferencias Panamericanas de Cancilleres. La posición estadounidense se fue alejando cada vez más de su posición intervencionista, a otra de colaboración denominada de "Buen Vecino", que se tradujo en una colaboración y una relación más estrecha y cordial entre Latinoamérica y Estados Unidos, no sólo militar para enfrentar la amenaza del fascismo, sino en un acceso más abierto al mercado estadounidense que benefició a ambas partes (Leonard y Bratzel, 2007). En el plano estratégico militar, el Gobierno estadounidense estableció una zona de seguridad que abarcó desde el Polo Norte hasta la Patagonia en el sur, como lo reconoció públicamente el presidente Roosevelt años después. La política de defensa continental, que fue

31. Todo este incidente es tratado de manera detallada por Chamberlin (1955). 
tejiendo pacientemente el Gobierno estadounidense a lo largo de esa década, permitió sin duda alguna enfrentar a Japón y a Alemania años después. ${ }^{32} \mathrm{Al}$ estallar la guerra, gracias a estos acuerdos previos se logró un amplio consenso a nivel panamericano en relación con los migrantes; durante la reunión de ministros de todo el continente en Río de Janeiro en enero de 1942, se acordó controlar a los "extranjeros potencialmente peligrosos, internar a los ciudadanos de los países del Eje y restringir absolutamente los procesos de naturalización de los mismos" (Kashima, 2003: 94). El involucramiento estadounidense entonces en dos frentes de guerra, en el Atlántico y en el Pacífico al mismo tiempo, no puede ser entendido sin el importante papel que cumplió la región latinoamericana para enfrentar a las potencias fascistas y sin la transformación de la política estadounidense hacia la región en su conjunto. ${ }^{33}$

En 1933, ocho años antes del ataque a Pearl Harbor, la preocupación estadounidense fue creciendo debido a la ocupación militar japonesa en China, pero además esta situación tuvo consecuencias directas en el continente americano al solicitar el mismo presidente Roosevelt a sus embajadas en América Latina informar el número de migrantes y la influencia de las comunidades de japoneses en cada país. A partir de ese año los reportes que elaboraban el Buró Federal de Investigaciones (FBI), la Oficina Naval de Inteligencia (ONI) y la División de Inteligencia Militar (MID) en las embajadas empezaron a poner atención en estos aspectos y en las actividades económicas que de manera directa Japón entablaba en esos países. La política de vigilancia sobre ese país se tornó tan importante como aquella que venía realizando sobre las actividades alemanas e italianas en el continente, que en conjunto formaron parte de la estrategia continental de defensa en todo el hemisferio. En la investigación de esos organismos de inteligencia se contabilizó en 170 mil el número total de japoneses y sus descendientes en Latinoamérica, siendo Brasil el principal receptor con 134 mil, seguido de Perú con 21 mil, México con seis mil y Argentina con cinco mil. ${ }^{34}$ Ante los vientos de guerra que eran

32. Para comprender la política hemisférica estadounidense en detalle y cómo se fue construyendo esta estrategia en relación con Latinoamérica como región integrada a Estados Unidos, consúltense Conn (1960) y Wood (1961). Una parte de esta política en relación con los japoneses en México puede ser vista en Hernández (2008).

33. Estos elementos son fundamentales para comprender la situación política en todo el continente en relación con Estados Unidos, pero además traerá repercusiones importantes al finalizar la guerra (Leonard y Bratzel, 2007; Haglund, 1984).

34. Franklin D. Roosevelt Library, Hyde Park, New York. President's Secretary's File. Mayo 21 de 1934. A partir de aquí FDRL. 
cada día más intensos, las políticas migratorias latinoamericanas igualmente se fueron adecuando a esta situación, transformándose a lo largo de esa década y haciéndose eco de un ambiente antijaponés creciente; por lo que se decretaron leyes restrictivas en varios países latinoamericanos (Barhart, 1962).

Ante el incremento de las diferencias entre Japón y Estados Unidos, para 1937 el presidente Franklin D. Roosevelt solicitó un informe detallado sobre las actividades de Japón en el continente. La investigación fue realizada por el Departamento de Guerra, y señaló que era "definitivamente evidente que las actividades japonesas se habían incrementado materialmente", tanto en el aspecto comercial como en el movimiento de agentes japoneses en la zona del Canal de Panamá, además de una nueva zona de colonización en Colombia. Respecto a México, el Departamento de Guerra señaló como exageradas las versiones de que en este país se asentaban cerca de 100 mil japoneses, y más bien estimó, de acuerdo con sus órganos de inteligencia, que en México radicaban entre 10 y 12 mil japoneses, por lo que decidió levantar una estimación exacta, especialmente en la zona fronteriza de Estados Unidos y México. El resultado de ese reporte dio cuenta con todo detalle de la población asentada en los estados de Baja California, Sonora, Sinaloa y Nayarit en el Pacífico, y los estados de la frontera con EU, ya que era considerada la zona más peligrosa en caso de guerra con Japón. La investigación de campo determinó que el numero de japoneses alcanzaba un total de 5,300 en toda la República y que de este total, 1,650 residían en Baja California y 850 en los restantes tres estados, como se puede apreciar en los mapas 2 y $3 .{ }^{35}$

La importancia estratégica que se le dio a la presencia japonesa abarcó no sólo a la población migrante asentada en los diversos países del continente americano. Los reportes de inteligencia incluyeron informes sobre las actividades de las embajadas japonesas y de los empresarios nipones que se involucraron de manera creciente en actividades comerciales. Se puso atención en el tipo de productos que compraban, las ramas económicas en las que se invertían y las personas y los organismos gubernamentales con los que se relacionaban. En este ambiente de preparación de la guerra, para el año de 1937 el MID le informó al presidente Roosevelt del aumento de las actividades comerciales de japoneses en la región, ${ }^{36}$ por lo que le solicitó, un

35. NARA R. G. 165. MID, 2655-G-235/31.

36. FDRL, President's Secretary's File. Julio 2 de 1937. 
año después, intensificar la vigilancia y aumentar los fondos especiales para realizar el espionaje sobre ellos. ${ }^{37}$

\section{Mapa 2}

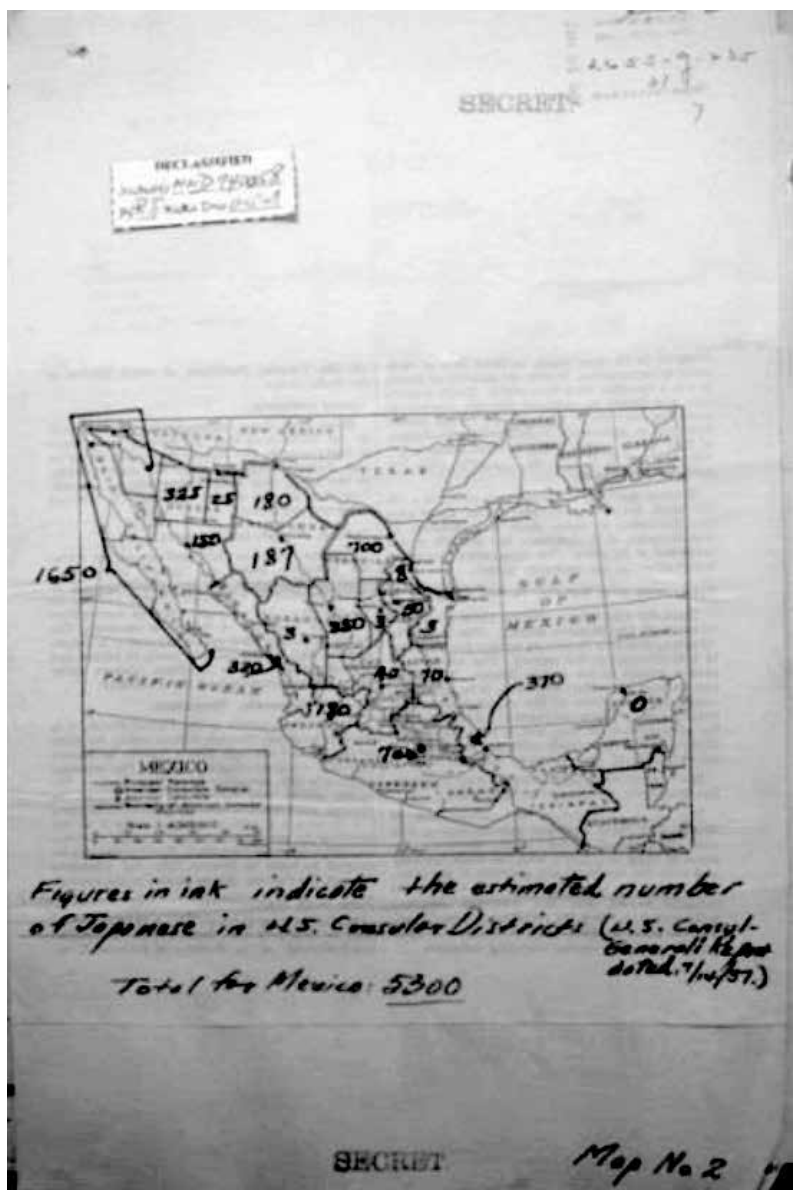

37. Informe enviado por el secretario de Guerra al presidente Roosevelt. NARA. R. G. 165 MID 2655-g174/27, marzo 12 de 1938. 


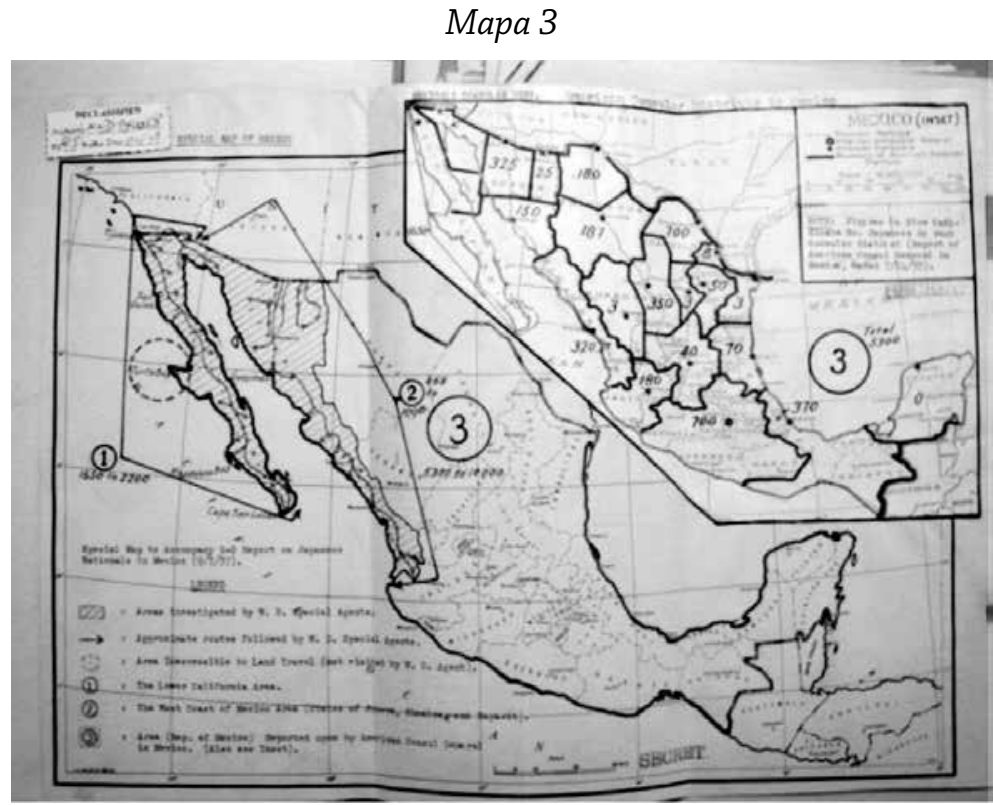

El Departamento de Estado no sólo se preocupó por las actividades de los empresarios japoneses y el número de migrantes en el continente, también consideró como un serio peligro para la seguridad estadounidense los fuertes lazos solidarios que tenían entre sí y con su patria. La comunidad japonesa había construido una serie de organizaciones como asociaciones locales y regionales que le permitían mantenerse informada y desarrollar una cohesión que en muchos casos no fue bien vista por los gobiernos de los países donde se asentaron. Igualmente la comunidad tenía una profunda simpatía con las políticas que el Gobierno japonés había puesto en práctica en los largos años de enfrentamiento con las potencias occidentales. Además el Gobierno japonés, mediante sus embajadas y consulados, buscó estrechar las relaciones con las comunidades asentadas en el continente, especialmente cuando el enfrentamiento con Estados Unidos se empezó a profundizar.

Estas circunstancias y la fuerte imagen de respeto y de veneración que los japoneses guardaban en torno al Tenno, ${ }^{38}$ dieron lugar a que los gobiernos y la

38. Es pertinente usar la palabra japonesa Tenno, en vez de emperador, pues su significado implica una connotación sagrado-religiosa y benevolente en sentido político. Véase al respecto Takabatake, 
prensa difundieran una imagen de los migrantes que los exhibía como un grupo homogéneo y fanático dispuesto a morir por su país y seguir al pie de la letra las órdenes del Gobierno japonés. Peor aún, empezaron a considerar a la comunidad japonesa en su conjunto como una columna invasora de la Armada Imperial japonesa en caso de guerra, una "quinta columna" en los países donde radicaba.

La idea profusamente difundida en torno a que los migrantes de ese origen representaban un peligro fue impulsada por la xenofobia de sectores racistas pero también por el Gobierno estadounidense como parte de la propaganda de guerra a nivel continental. El propósito de esta propaganda era atemorizar a la población para poder justificar las medidas discriminatorias y represivas contra los migrantes y, al mismo tiempo, para que ésta se sumara a la lucha contra Japón. En México el gobierno de Manuel Ávila Camacho informó al estallar la guerra sobre una supuesta invasión japonesa con objeto de que la población apoyara la política estadounidense y se estableciera una alianza estratégica al lado de ese país, alianza que no era bien vista por la mayoría de la población.

El temor a Japón no sólo consistió en su fuerza económica y su política imperial que efectivamente se fue imponiendo en unas cuantas décadas; existió un temor racial, como lo muestra con claridad el informe que el embajador estadounidense en Tokio le envió al presidente Roosevelt ocho años antes de que estallara la guerra:

Más que su tamaño o la fuerza de su maquinaria de guerra (de Japón) [...] lo que lo hace amenazante es la fuerza en su moral nacional y su espíritu de cuerpo, quizá no igualado desde los días cuando las hordas mongolas siguieron a Gengis Khan en su conquista de Asia. ${ }^{39}$

\section{Japón en busca de materias primas}

A este ambiente enrarecido por la propia dinámica de enfrentamiento entre ambas potencias, se sumó el interés estratégico que el imperio japonés le empezó a imprimir a sus relaciones con México y con Latinoamérica en general. La política exterior japonesa significó agregar gasolina al fuego de la

Knauth y Tanaka (1992: 12). Igualmente si se quiere profundizar sobre la política japonesa, los dos volúmenes de estos autores resultan de gran utilidad debido a la gran cantidad de documentos traducidos, necesarios para entender la historia de Japón a lo largo de este periodo.

39. FDRL, President's Secretary's File, Diplomatic Correspondence Japan, informe del agregado militar de la embajada estadounidense en Tokio, mayo 11 de 1933. 
desconfianza que el Gobierno estadounidense guardaba sobre las intenciones del Gobierno imperial en la región. Japón no sólo adquirió petróleo, compraba otras materias primas estratégicas para la guerra, como mercurio y espato de flúor y además sostenía acuerdos binacionales en actividades pesqueras en diversos países, entre ellos México.

Un primer gran impulso del comercio exterior japonés con América Latina se presentó durante el periodo de 1915-1929. Japón, al participar en la Primera Guerra Mundial de manera más bien modesta, no le significó un desangramiento de su economía, sino por contrario le permitió mejorar su balanza de pagos debido al incremento de sus exportaciones de 1914-1918 en más de 3.3 veces, mientras que sus importaciones lo hicieron sólo en 2.8 veces, por lo que pudo lograr un superávit de 1,408 millones de yenes (Shinohara, 1962: 54). El siguiente impulso económico, después de la recesión mundial que significó el crack de 1929, estuvo ligado a la ocupación de China en 1931 y a la preparación de la guerra en los siguientes años, lo que representó una gran expansión de su economía, además de un gran involucramiento geoestratégico como gran potencia en la gran faja del Pacífico asiático. Por otra parte, el interés de Japón en varios países latinoamericanos para extender su comercio hizo que el periódico New York Times fuera uno de los primeros en informar de manera alarmista de la expansión japonesa en Latinoamérica, al señalar que el aumento de las exportaciones con los países de la región, en detrimento de los exportadores estadounidenses, se había incrementado en más de mil por ciento de 1932 a 1933. El artículo señaló igualmente que el Gobierno de ese país era el principal promotor de esa expansión, por lo que los agregados comerciales y diplomáticos estadounidenses reportarían con detalle esa situación. ${ }^{40}$

En efecto, existieron razones estructurales que impulsaron un interés creciente de la política japonesa hacia América Latina debido a que su economía, ante el explosivo crecimiento y escasez de materias primas, se hizo cada vez más dependiente de las importaciones de las mismas. En la década de los treinta el crecimiento de la producción industrial fue de $7.5 \%$ y el crecimiento de sus exportaciones alcanzó $8.5 \%$. La dependencia en la importación de materias primas creció enormemente del año 1902 a 1937 de 31 a 60\%;11

40. The New York Times, “Japan trade gains stir us to action", mayo 2 de 1934. A partir de aquí NYT.

41. Datos de Nihon keizai-Tokeishu (Estadísticas de la economía japonesa) y Nippon Tokei Kenkyusho (Instituto de Investigaciones sobre las Estadísticas de Japón). Tomado de Shinohara (1962: 43-55). 
más aún, en gasolina y otros productos petroleros las compras del exterior alcanzaron $91 \%$ de su consumo total al acercarse la guerra. ${ }^{42}$ Otro factor vital que orilló a Japón a buscar fuentes alternas de aprovisionamiento fue el hecho de que los países ocupados en Asia, básicamente la región china de Manchuria, no lograron cubrir la demanda creciente para surtir una economía de guerra (Stewart, 1940). En ese sentido las misiones comerciales japonesas hacia Latinoamérica se hicieron más frecuentes con el propósito de atender estas debilidades, pero a la par que aumentaba el interés en América Latina, al mismo tiempo la vigilancia y los reportes de las embajadas y la prensa estadounidenses sobre las mismas se hicieron más frecuentes. ${ }^{43}$

Aunque el crecimiento de la actividad comercial de Japón con América Latina fue espectacular, sólo representó $2 \%$ del total de las importaciones de la región, mientras que el porcentaje de exportación más alto de un país latinoamericano hacia ese país nunca rebasó $5 \%$ de su total. ${ }^{44}$ Los incrementos en los niveles de intercambio comercial con Japón en realidad nunca representaron una amenaza para los intereses económicos estadounidenses o británicos. Por tanto, los informes de la penetración japonesa obedecieron más bien al enfrentamiento progresivo entre Japón y Estados Unidos y a la visión geoestratégica de la guerra que este último país empezó a considerar como una posibilidad creciente.

Las relaciones diplomáticas entre los Gobiernos de México y Japón durante el periodo de Lázaro Cárdenas (1934-1940) empezaron a ser más cordiales por varias razones, como veremos adelante, aunque la posición antifascista del gobierno cardenista sólo estuvo puesta en duda por los sectores más conservadores del Gobierno estadounidense, que atacaron duramente la posición nacionalista del presidente mexicano. El acercamiento se debió en primer lugar a la política cardenista de buscar alternativas de inversión e intercambio comercial, ante su excesiva dependencia del mercado estadounidense y, sin duda, como respuesta a la presión de los Gobiernos de Estados Unidos y Gran Bretaña, que buscaban echar atrás la política antiimperialista del gobierno cardenista y en particular la expropiación de las compañías petroleras extran-

42. Navy Departement, Office of Naval Inteligence (ONI), Report on Petroleum Situation of Japan, 12 de marzo de 1941. NARA. Record Group 38. Office of the Chief of Naval Operetions.

43. El ministro Kanzo Shiozaki, encargado del Departamento para América del Ministerio de Relaciones Exteriores, señaló la excelente relación que existía con la región y el interés de comprar una serie de materias primas necesarias para Japón. NYT, junio 25, 1940.

44. Perú y Paraguay eran esos países (Porter, 1935). 
jeras. Japón ofrecía productos que el mercado mexicano demandaba, como la artisela, producto de alto consumo popular, mientras que Japón por su parte requería de materias primas que México tenía en abundancia. Si revisamos la composición del comercio entre México y Japón durante esta década, veremos con claridad cómo éste se fue orientando al acercarse la guerra cada vez más en la búsqueda de materias primas estratégicas para la misma. A principios de esos 10 años los bienes que importó Japón fueron básicamente algodón en rama; pero al acercarse el ataque a Pearl Harbor, el petróleo, plomo, zinc y mercurio se convirtieron en los bienes mayormente demandados. En cambio México se orientó a lo largo de la década a la importación de productos textiles y otros de consumo final. ${ }^{45}$

Otro cambio en la política japonesa, fue su relación con los miles de migrantes de ese origen que radicaban en todo el continente americano. Las embajadas japonesas en el continente reforzaron de manera más estrecha su trato con las comunidades de migrantes con el propósito, en primer lugar, de que apoyaran activamente los planes expansionistas que habían puesto en marcha en Asia y, en segundo lugar, que pudieran servir como fuente de información y de relación con la política comercial del Imperio en la región. Un ejemplo de la puesta en práctica de estas medidas lo representa el caso de un emigrante japonés en México, Kiso Tsuru, quien desempeñó un papel importante en el suministro de una serie de materias primas que se consideraron estratégicas para la política expansionista japonesa.

\section{La nacionalización del petróleo: Japón y el boicot de Estados Unidos al comercio mexicano}

El "doctor Tsuru”, como era conocido en México, poseía un gran número de empresas. La más antigua de ellas era la Compañía Internacional de Drogas fundada en 1928, empresa que produciría años después el famoso ungüento Vitacilina que se sigue comercializando en nuestros días. El involucramiento de Tsuru en el comercio y la producción de materias primas estratégicas para la guerra como el petróleo, el espato de flúor y el mercurio hicieron que la inteligencia estadounidense y británica vigilara de cerca a este empresario. Además su participación en la construcción de carreteras y en la industria pesquera (actividades que le

45. La lista de los productos que constituyeron el comercio entre México y Japón de 1920 a 1942 se puede consultar en la serie de estadísticas compiladas por Uscanga (2013). 
permitían tener acceso a información del territorio y de las costas nacionales) fue ampliamente difundida por la prensa estadounidense, que le dedicó extensos reportajes pues afirmaba que era la punta del iceberg de la intervención japonesa en México. ${ }^{46}$ Por si fuera poco, además de poseer este complejo industrial y comercial, Tsuru había tejido una serie de relaciones con destacados empresarios y políticos de México y Japón, del que había emigrado a principios de la década de los años veinte.

La vigilancia que el Gobierno estadounidense mantuvo sobre México, puso énfasis en la comercialización y producción de una materia prima estratégica: el petróleo. México se había convertido en un gran productor y exportador de ese energético a nivel mundial desde las primeras décadas del siglo xx; la producción pasó de sólo 10 mil barriles en el año 1900 a 193 millones en 1921, su nivel más alto hasta antes de la guerra (INEGI, 2000: 477). Esta capacidad de producción atrajo el interés de Japón desde ese entonces, por lo que un joven japonés miembro de la Armada Imperial, Isoruko Yamamoto, justo en ese último año visitó el puerto de Tampico ante la fama mundial que había alcanzado la productividad de los pozos petroleros mexicanos. ${ }^{47}$

Para 1938 el presidente Lázaro Cárdenas tomó la decisión de expropiar esa estratégica industria que se encontraba en su mayoría controlada por compañías británicas y estadounidenses. Al momento de la expropiación petrolera, los conflictos internacionales se iban agravando día a día: Japón había desatado la guerra total contra China e inició a finales de ese año su política de construir el "nuevo orden" para el este de Asia. En Europa, las fuerzas armadas de Hitler ocuparon Austria y parte de Checoslovaquia. La expropiación petrolera en ese contexto no sólo afectó los intereses estadounidenses y descompuso las relaciones entre México y Estados Unidos, sino destapó una "caja de Pandora" al reacomodar las complejas relaciones que a nivel político y comercial mantenía México con Japón y Alemania.

La primera represalia que tomaron las compañías extranjeras expropiadas, junto con los Gobiernos británico y estadounidense, fue bloquear el comercio exterior del petróleo mexicano. Ante esta medida, el presidente Cárdenas se vio

46. Consúltese esta extensa información sobre Tsuru en NYT, "Japan to expand trade with Mexico", 28 de enero de 1940. NYT, "Japanese activity in Mexico growing", 7 de julio de 1940.

47. Yamamoto estudiaba en la Universidad de Harvard en ese entonces; se convertiría al pasar de los años en el almirante encargado de elaborar los planes de ataque de la flota japonesa contra Pearl Harbor. La relación que Tsuru mantenía con el almirante, así como la magnitud de los negocios de éste son detalladas en Hernández (2011). 
obligado a tomar una serie de decisiones para evitar se ahorcara a la economía mexicana mediante el cierre de sus ingresos petroleros. La política cardenista fue muy clara y firme, pues decidió que si Estados Unidos y Gran Bretaña no compraban el petróleo mexicano, éste se vendería a cualquier país que lo demandara, fuera Alemania, Italia o Japón. El periódico New York Times publicó que la nacionalización del petróleo significaba un desafío a la política estadounidense de Buen Vecino y que tal medida significaba un acercamiento con Japón, dado que ese país estaba muy interesado en la adquisición del petróleo mexicano. El objetivo del diario era presionar al Gobierno estadounidense para que actuara en contra de la expropiación, pues además sostenía que la política del Gobierno mexicano se encontraba cada vez más cercana a las naciones fascistas, países que trabajaban en coordinación estrecha, según el diario, para apropiarse del petróleo mexicano. Además el periódico afirmó que el Gobierno estadounidense había dejado manos libres para que un gobierno "socialista" expropiara los bienes de las compañías extranjeras. ${ }^{48}$

Con objeto de presionar más aún al gobierno cardenista, el Gobierno estadounidense decidió limitar las cuotas de compra de plata mexicana a un acuerdo mensual renovable. Sin la exportación de ese metal y del petróleo, los ingresos mexicanos se colapsarían brutalmente; el bloqueo estadounidense al petróleo mexicano significó la disminución en ventas de 25 millones a 15 millones de barriles y con ello los ingresos cayeron abruptamente en 50\% al pasar de 162 millones de pesos a sólo 80 millones a finales de 1938 (Powell, 1956: 112).

El presidente Cárdenas dio inicio, ante esta situación, a una política comercial que consistió en intercambiar, mediante el trueque, productos que el país necesitaba a cambio de petróleo. Mediante este mecanismo se adquirieron maquinaria y refacciones que la industria petrolera necesitaba, además de productos de consumo como hilo y rayón que serían intercambiadas con Alemania e Italia, mientras que de Japón se importó artisela, producto que era fuertemente demandada por el mercado mexicano. Esta forma de sortear el embargo comenzó de nuevo a desatar fuertes críticas en los círculos intervencionistas estadounidenses, que señalaron que en efecto existía un acercamiento del Gobierno mexicano con las dictaduras fascistas y que la influencia de éstas era creciente en el mercado

48. Los reportes del diario reflejaban muy bien los puntos de los sectores más conservadores, aliados a los de las compañías petroleras, que promovían una actitud intervencionista hacia México. Véase al respecto el NYT del 27 de marzo de 1938 y del 16 de agosto de 1938. 
mexicano. ${ }^{49}$ Por su parte el Gobierno estadounidense solicitó a sus embajadas en Latinoamérica supervisar con cuidado todas las ventas de petróleo mexicano al exterior para valorar los resultados del embargo y medir con exactitud tanto el comportamiento del gobierno de Cárdenas como la influencia real de los países fascistas en el comercio mexicano. ${ }^{50}$

Años antes de la expropiación, el interés de Alemania y Japón para comprar petróleo fue expresado claramente al Gobierno mexicano. Estos países buscaban fuentes alternas de aprovisionamiento del energético ante la inminencia de la guerra, por lo que al consumarse la nacionalización, ambos países se pusieron de acuerdo con el gobierno del presidente Cárdenas para adquirir los excedentes petroleros que los países afectados por la expropiación rechazaban. Japón en 1938 sólo producía $15 \%$ del total del petróleo que consumía, por lo que el embajador japonés en México, Soichiro Koshida, le manifestó al Gobierno mexicano su disposición inmediata de comprar crudo mexicano, anunciando la compra de 100 mil barriles de crudo que saldrían del puerto de Tuxpan, Veracruz, hecho que la prensa estadounidense informó de inmediato y que la Embajada reportó a Washington. ${ }^{51} \mathrm{Al}$ año siguiente, Koshida, mediante un cable que envió a la cancillería en Tokio, la puso al tanto de los problemas económicos por los que atravesaba el gobierno de Cárdenas debido al boicot de sus exportaciones, por lo que aconsejó a su gobierno que era el momento de profundizar las relaciones comerciales con México, no sólo en cuanto a la compra de petróleo, sino en otros ámbitos que serían de utilidad para ambos países. ${ }^{52}$

Como si esto no fuera grave para los intereses estadounidenses, Cárdenas en 1940 amplió hasta 100 mil hectáreas los permisos de concesiones de exploración y explotación del hidrocarburo a dos compañías: La Laguna y La Veracruzana, que eran propiedad de Tsuru y que se habían constituido en 1935 y 1936 respectivamente. ${ }^{53}$ Estas compañías legalmente no eran propiedad de algún extranjero, pues Tsuru se había naturalizado mexicano años atrás; sin embargo, la inteligencia estadounidense sospechaba que detrás de

49. Consúltese NYT, octubre 29 de 1938.

50. NARA, Record Group 59, General Records of the Department of State, DS 812.6363/660, informe enviado por la embajada estadounidense en México al Departamento de Estado, marzo 12 de 1940. A partir de aquí NARA, R. G. 59.

51. NYT, 27 de marzo de 1938.

52. NARA, Record Group 457, Records of the National Security Agency, From Mexico to Tokyo, septiembre 11 de 1939. De aquí en adelante NARA, R. G. 457.

53. Junto con Tsuru, importantes políticos y empresarios mexicanos formaban parte del grupo de accionistas, como Modesto C. Rolland, Carlos Almazán y Jesús Villaseñor, entre otros. 
la inversiones de Tsuru en éstos y otros negocios se encontraban capitales privados japoneses e incluso del mismo Gobierno japonés, ${ }^{54}$ probablemente del Ministerio de Marina, que estaba muy interesado en buscar proveedores alternos del energético y romper de esta forma la dependencia de fuentes de aprovisionamiento estadounidenses, país del cual provenía 85\% del total de su importaciones en 1938 (Miller, 2007: 157). Aunque estas dos compañías no llegaron a producir altos volúmenes de petróleo, el conocimiento que pudieran tener del territorio nacional fue la razón principal de preocupación de los estrategas estadounidenses (véase Mapa 4)..$^{55}$

\section{Mapa 4}

Principales campos petroleros reportados por La Laguna

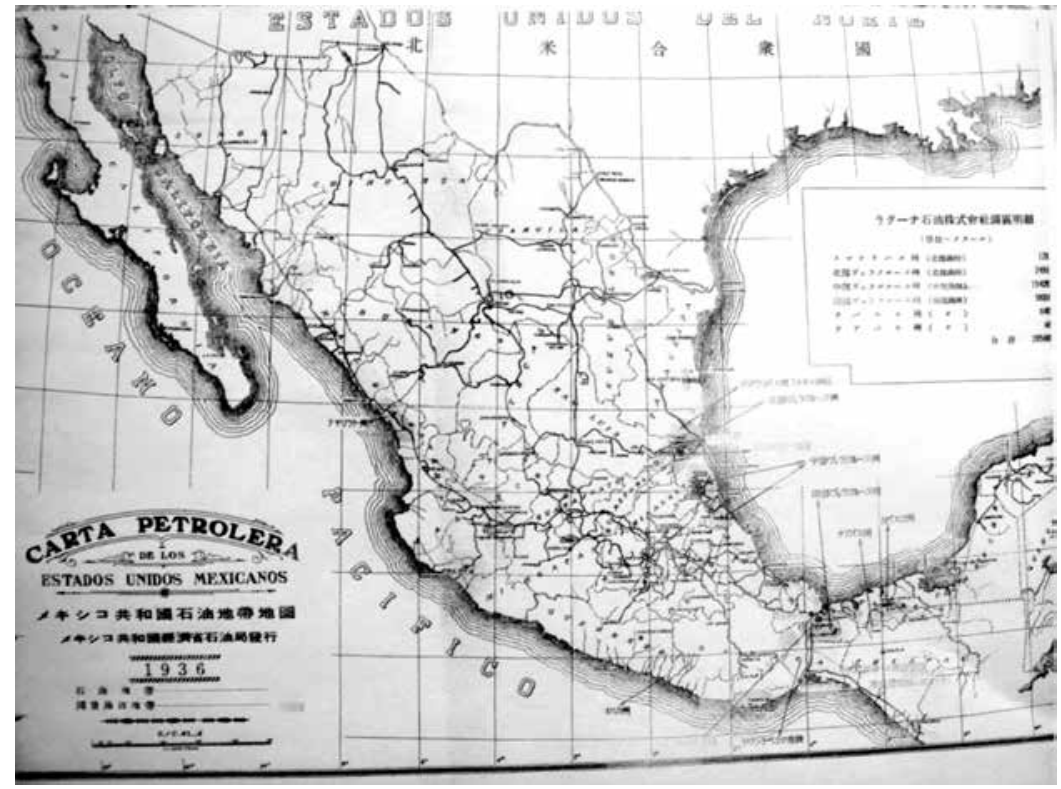

Otra probable inversión japonesa que se anunció fue la construcción de un oleoducto que uniría los océanos Atlántico y Pacífico, atravesando el Istmo de Tehuantepec, desde Minatitlán, Veracruz, hasta Salina Cruz, Oaxaca. La construcción de este oleoducto permitiría la exportación de petróleo hacia Japón de

54. NARA, R. G. 165. Mid. 2655-g-226/9. Enero de 1938.

55. Informe de labores de la Compañía Petrolera La Laguna, 1936. 
manera más económica y rápida, al no tener que rodear los embarques por el Canal de Panamá. El embajador Koshida confirmó la información y señaló que a cambio de la venta de medio millón de barriles al año, su país colaboraría en la construcción de ese oleoducto cuyo costo, se dijo, ascendía a 25 millones de pesos. ${ }^{56}$ En marzo de 1940, una misión comercial mexicana, encabezada por funcionarios y empresarios mexicanos, realizó una gira por Japón para explorar mejores y mayores intercambios comerciales y de inversión entre ambos países. El New York Times reportó que México iba a ofrecer petróleo y otras materias primas a cambio de seda y facilidades para que se instalaran industrias manufactureras japonesas. ${ }^{57}$

La política del presidente Cárdenas se mantuvo firme, pues a pesar de las presiones de las compañías expropiadas y de sus gobiernos, México siguió surtiendo petróleo a Alemania, Italia y Japón. A un año de la expropiación, gracias a las compras de esos países y de las propias compañías importadoras estadounidenses que no estaban dispuestas a salirse de tan jugoso negocio, las ventas de la industria nacionalizada no experimentaron una baja considerable como deseaban las petroleras expropiadas y los sectores más conservadores del Gobierno estadounidense. ${ }^{58}$ Japón, a pesar de su interés en el petróleo mexicano durante 1938 y 1939, no estuvo plenamente convencido de surtirse del energético de manera permanente debido a los altos costos que significaba transportarlo por el Canal de Panamá. Fue hasta 1940 cuando Japón intentó seriamente, aun a pesar del precio, buscar un acuerdo formal de compra del crudo mexicano debido a la amenaza estadounidense de embargar las exportaciones de crudo a Japón, embargo que se hizo realidad a mediados de 1941. Pero buscar un acuerdo definitivo ya era demasiado tarde: el gobierno de Cárdenas, ante el escalamiento de la guerra en Europa y el creciente expansionismo de Japón en Asia, decidió alejarse de cualquier negociación comercial tanto con Japón como con Alemania y sumarse a la política del presidente Roosevelt en su política contra los países fascistas que formalmente anunciaron un acuerdo militar y político en septiembre de 1940, constituyéndose el Pacto del Eje Berlín-Roma-Tokio.

56. NYT, 24, 26 y 27 de marzo de 1938. Las embajadas estadounidense e inglesa enviaron reportes precisos a sus gobiernos sobre esta posible inversión.

57. NYT, 18 de marzo de 1940.

58. México vendió del total de sus exportaciones petroleras $48 \%$ a Alemania, $17 \%$ a Italia y a Japón sólo una pequeña cantidad. Estados Unidos siguió comprando petróleo aun a pesar de la campaña de boicot, alcanzando 20\% del total (Meyer, 2009: 199-242). 
A este acercamiento entre México y Estados Unidos, sin duda ayudó la decisión del presidente Roosevelt de no presionar más a su vecino al considerar que era fundamental marchar unidos ante la extensión de la amenaza del fascismo. Las presiones para ahorcar a México en su comercio exterior no contaban con el acuerdo unánime del Gobierno estadounidense aun desde la misma expropiación petrolera de marzo de 1938. El embajador estadounidense en México, Josephus Daniels, era el más reacio para tomar medidas extremas contra el Gobierno mexicano, pues sostenía que la política del Buen Vecino era fundamental para preservar la "unidad del hemisferio en un mundo loco", puesto que consideraba que Cárdenas estaba realmente comprometido con los países que luchaban contra el fascismo. El embajador, poco después de la expropiación petrolera, le escribió dos extensas cartas personales al presidente Roosevelt donde le explicó que aun cuando consideraba un error la medida expropiatoria, el "petróleo no debería manchar la política de solidaridad continental” y que la política de buena vecindad debería estar por encima de los intereses de las compañías petroleras. ${ }^{59}$

La necesidad del energético para los estadounidenses, que ya veían inminente la guerra, fue el factor fundamental para detener el escalamiento del conflicto con el Gobierno mexicano y buscar un arreglo amistoso entre ambos, dejando de lado los intereses de las compañías expropiadas. El aprovisionamiento mexicano del energético era vital en tiempos de guerra de acuerdo con los estudios que le fueron encomendados por Roosevelt a Harold L. Ickes, quien además de ser secretario del Interior del Gobierno estadounidense, coordinaba los estudios sobre el petróleo para la defensa nacional. Ickes aconsejó al presidente Roosevelt la necesidad de adquirir petróleo del exterior debido a que las reservas estadounidenses venían cayendo desde 1933. En este contexto y ante la inminencia de la guerra, la fuente mexicana del energético resultaba fundamental para Estados Unidos, por lo que Ickes impulsó un arreglo definitivo con México sobre los diferendos que la expropiación mexicana de 1938 arrastraba en las relaciones bilaterales, acuerdo al que el presidente Roosevelt aceptó. El mismo Ickes igualmente reconoció que la defensa de las compañías expropiadas no tenía sentido desde el punto de vista del interés estratégico de Estados Unidos, a sabiendas que éstas sólo defendían

59. En esta misma carta le menciona que las compañías petroleras sólo pensaron en sus ganancias cuando en México apoyaron a Victoriano Huerta en 1911, quien asesinó al presidente constitucional Francisco I. Madero, aun cuando la política del presidente estadounidense Wilson era de no reconocer al usurpador. FDRL, President's Secretary's File, marzo 22 de 1938 y marzo 29 de 1938. 
sus propias ganancias. ${ }^{60}$ Para fines de 1941, del total de la producción mexicana, 92\% se exportó a Estados Unidos (Paz, 1997: 88).

\section{El camino hacia la guerra total}

La migración japonesa que había sido bienvenida al continente a finales del siglo XIX, especialmente en México y Estados Unidos, fue poco a poco convirtiéndose en una amenaza para la seguridad estadounidense en la medida en que Japón se fue transformando en gran potencia. Al acercarse la Guerra del Pacífico, la coraza de seguridad que el Gobierno estadounidense levantó en todo el continente americano, hizo que los migrantes fueran considerados como una "quinta-columna" de una supuesta invasión de la Armada Imperial japonesa.

Por otro lado, la larga etapa de crecimiento económico que se inició en 1868 en Japón y que fue auspiciada por la expansión de la economía-mundo en la que Estados Unidos fue erigiéndose en el centro hegemónico, dio paso a un intenso intercambio de mercancías y traslado de cientos de miles de seres humanos. A partir de ese entonces, los mares del Pacífico que separaban a estos países fueron los conductos por los cuales las economías de Japón y Estados Unidos se convirtieron en socios privilegiados. ${ }^{61}$ México en la década anterior al inicio de la guerra, ubicado en la periferia de ese sistema-mundo, al compartir una extensa frontera común con Estados Unidos, ser destino de migrantes japoneses y poseer una serie de recursos naturales (como el petróleo) que movían las economías y los ejércitos de las potencias, se fue convirtiendo en un escenario protagónico de las disputas de las potencias y de la guerra total en que se enfrascarían.

El Pacífico, por el que transitaron y se consolidaron los lazos comerciales y migratorios se tornó en un océano de desconfianza y boicot en la medida en que Japón y Estados Unidos se fueron convirtiendo en potencias con proyectos hegemónicos encontrados: sus intereses geoestratégicos eran demasiado grandes para convivir en el vasto océano, que ya no era capaz de contenerlos, como el almirante Mahan había previsto desde principios de siglo. ${ }^{62}$ La economía japonesa dependía,

60. Carta de Ickes al presidente Roosevelt. Biblioteca del Congreso, Harold Ickes Papers, citado en Paz (1997: 89).

61. De un intercambio comercial minúsculo al inicio de Meiji en 1868, para 1930 del total de exportaciones japonesas, $37 \%$ se dirigían a EU, mientras que importaba de ese país cerca de $25 \%$ (Beasley, 1990: 127).

62. Desde esta perspectiva, el estudio de Iriye (1972) aclara las raíces históricas del enfrentamiento entre las nacientes potencias a principios del siglo $\mathrm{xx}$. 
como hemos visto, de manera excesiva del petróleo para mover su maquinaria de guerra, por lo que el embargo de facto decretado por el Gobierno estadounidense en agosto de 1941 fue considerado de hecho por Japón como una declaración de guerra; un mes antes el presidente Roosevelt había congelado los activos japoneses, medida que fue seguida por Inglaterra, con lo que prácticamente quedaba cercenada de raíz cualquier posibilidad de negociación y acuerdo entre ambos países, pues Japón por su parte había decidido no retroceder en la serie de posiciones que había conquistado, particularmente en China y en toda Asia.

La estrategia de autarquía del Imperio japonés que fue elaborada por los altos mandos militares desde finales de la Primera Guerra Mundial con el propósito de estar preparados para una posible guerra, estaba a punto de entrar en acción. Mediante esta estrategia Japón organizó una fuerza militar capaz y disciplinada que enfrentara a los grandes poderes, pero además concebía que una guerra no sólo se podía ganar mediante la fuerza militar, para ello habría que poner en juego todos los recursos de la nación: desde el algodón al acero, por un lado; y desde los ingenieros hasta los doctores, por otro. ${ }^{63}$ Esta estrategia, sin embargo, se fue moldeando y calibrando al calor de su enfrentamiento con los intereses estadounidenses no sólo en Asia sino en México mediante una serie de medidas muy puntuales de las que en el plano comercial y diplomático he dado cuenta. En agosto de 1941 ninguno de los contrincantes parecía desear la guerra, por lo que hubo intensas negociaciones para detenerla, pero a esas alturas ya nadie podría hacerlo. Cuando estalló la guerra, por el Pacífico sólo transitarían las armas con el único propósito de destrucción total del enemigo.

\section{Fuentes de información}

\section{Archivos}

Archivo General de la Nación, AGN. México.

Fondo de la Dirección de Investigaciones Políticas y Sociales de la Secretaría de Gobernación.

National Archives and Records Administration, Washington, DC.

Record Group 38, Office of the Chief of Naval Operations.

63. Barnhart (1987) estudia de manera puntual las condiciones históricas bajo las cuales Japón fue poniendo en práctica una serie de medidas que le permitieran enfrentar en el plano tanto interno como externo una posible guerra. 
Record Group 59, General Records of the Department of State.

Record Group 165, Records of the War Department, Military Intelligence

Division (MID).

Record Group 457, Records of the National Security Agency.

Franklin D. Roosevelt Library, Hyde Park. New York.

President's Secretary's File.

President's Personal's File.

Periódicos

New York Times.

\section{Bibliografía}

Azuma, Eiichiro (2005), Between Two Empires. Race, History, and Transnationalism in Japanese-America, Oxford: Oxford University Press.

Bairoch, Paul (1982), "International Industrialization. Levels from 1750 to 1980”, Journal of European Economic History 11(2), pp. 269-325.

Barnhart, Edward N. (1962), "Citizenship and Political Tests in Latin American Republics in World War II”, Hispanic American Review, 42(3), pp. 297-332.

Barnhart, Michel A. (1987), Japan Prepares for Total War. The search for economic security, 1919-1941, Ithaca: Cornell University Press.

Beasley, W. G. (1990), Japanese Imperialism 1894-1945, Oxford: Oxford University Press.

Chamberlin, Eugene Keith (1955), "The Japanese Scare at Magdalena Bay”, Pacific Historical Review, 24(4), pp. 345-359.

Conn, Stetson, y Fairchild, Byron (1960), The Framework of Hemisphere Defense, Washington: Office of The Chief of Military History.

Daniels, Roger (1977), The Politics of Prejudice. The Anti-Japanese Movement in California and the Struggle for Japanese Exclusion, Berkeley: California University Press.

Díaz Covarrubias, Francisco (2008), Viaje al Japón, México: Ediciones de Educación y Cultura FONCA.

Dower, John W. (1986), War without mercy. Race \& Power in the Pacific War, Nueva York: Pantheon Books.

Estes, Donald (1977), "Kondo Masaharu and the Best of All Fishermen", The Journal of San Diego History, 23(3), pp. 9-47. 
García, Genaro (1911), Crónica oficial de los festejos de las Fiestas del Primer Centenario de la Independencia de México, México: Talleres del Museo Nacional. Glick Schiller, Nina, Linda Basch, y Cristina Szanton Blanc (eds.) (1993), Nations Unbound: Transnational Projects, Postcolonial Predicaments, and Deterritorialized Nation-States. Inglaterra: Gordon and Breach.

Haglund, David G. (1984), Latin America and the transformation of U. S. Strategic Thought, 1936-1940, Alburquerque: New Mexico University Press.

Hernández Galindo, Sergio (2003a), "Empresarios y política industrial: Un estudio histórico comparado entre México y Japón", Antropología 72. Boletín Oficial del Instituto Nacional de Antropología e Historia, México, pp. 22-41. (2003b), "Las empresas de los inmigrantes japoneses en México. El caso de la familia Kasuga”, en Rosa María Meyer y Delia Salazar (coord.), Los inmigrantes en el mundo de los negocios, México: Plaza y Valdez.

(2008), "La guerra interna contra los japoneses", Dimensión Antropológica, núm. 43, México: Revista del Instituto Nacional de Antropología e Historia.

(2011), La guerra contra los japoneses en México durante la Segunda Guerra Mundial. Kiso Tsuru y Maso Imuro, migrantes vigilados, México: Ítaca.

Hobsbawm, Eric (2007), Guerra y paz en el siglo XXI, Barcelona: Crítica.

Ichioka, Yuji (1980), The Issei. The World of the First Generation of Japanese Immigrants 1885-1924, Nueva York: Free Press.

Instituto Nacional de Estadística, Geografía e Informática (INEGI) (2010), Estadísticas históricas de México 2009, II tomos, Aguascalientes: INEGI.

Iriye, Akira (1972), Pacific Estrangement, Japanese and American Expansion 1897-1911. Cambridge: Harvard University Press.

Irokawa, Daikichi (1985), The culture of the Meij Period, Nueva Jersey: Princeton Library of Asian Tranlations.

Kashima, Tetsuden (2003), Judgment without trial, Japanese American Imprisonment during World War II. Seattle: Washington University Press.

Katz, Friedric (1982), La guerra secreta en México, México: Ediciones ERA.

LaFeber, Walter (1997), The Clash. U. S.-Japanese Relations throughout History. Nueva York: Northon \& Company.

Meyer, Lorenzo (2009), Las raíces del nacionalismo petrolero en México. México: Océano de México.

Miller, Edward S. (2007), Bankrupting the Enemy. The US Financial Siege of Japan before Pearl Harbor. Maryland: Naval Institute Press. 
Ministerio de Asuntos Exteriores de Japón (1971), Waga Kokumin no Kagai Hatten (La expansión de nuestro pueblo), Tokio: Departamento de Inmigración, Estadísticas de Inmigración.

Nakamura, Takajusa (1980), Economía japonesa: Estructura y desarrollo. México: El Colegio de México.

Neumann, William L. (1953), "Franklin D. Roosevelt and Japan, 1913-1933”, Pacific Historical Review, 22(2), pp. 143-153.

Niiya, Brian (ed.) (2001), Encyclopedia of Japanese American History. Nueva York: Checkmark Books.

Nishikawa Aceves, Kiyoko (2002), "La comunidad japonesa en Ensenada", Memoria del Seminario de Historia de Baja California, México: Universidad Autónoma de Baja California.

Ota Mishima, María Elena (1976), México y Japón en el siglo XIX. La política exterior de México y la consolidación de la soberanía japonesa, México: Secretaría de Relaciones Exteriores.

-_ (1982), Siete migraciones japonesas en México, 1890-1978, México: El Colegio de México.

Paz, María Emilia (1997), Strategy, Security, and Spies. Mexico and The U. S. as Allies in World War II, Pennsylvania: The Pennsylvania State University Press.

Porter, Catherin (1935), “Japanese 'penetration' of Latin America”, Far Eastern Survey, 4(10), pp. 73-78.

Powell, J. Richard (1956), The Mexican Petroleum Industry, 1938-1950, Berkeley: California University Press.

Rankin, Monica A. (2009), México, la Patria. Propaganda and Production during World War II, Lincoln/Londres: University of Nebraska Press.

Robinson, Greg (2001), By Order of The President. FDR and the Internment of Japanese Americans, Cambridge: Harvard University Press.

Shinohara, Miyohei (1962), Growth and Cycles in the Japanese Economy, Tokio: The Institute of Economic Research Hitotsubashi-University Kinokuniya. Stewart, John R. (1940), "The Yen-Bloc Supply Base in Practice", Far Eastern Survey, 9(11), pp. 123-129.

Takabatake, Michitoshi, Knauth, Lothar, y Tanaka, Michiko (comps.) (1987), Política y pensamiento político en Japón. 1868-1925, México: El Colegio de México.

-_ (1992), Política y pensamiento político en Japón, 1926-1982, México: El Colegio de México. 
Ueno, Hisashi (s/f), Los samuráis de México. La verdadera historia de los primeros inmigrantes japoneses en Latinoamérica, México: Asociación MéxicoJaponesa.

Uscanga, Carlos (2013), Las relaciones económicas de México y Japón en el preludio de la Guerra del Pacífico, México: Conacyt.

Wood, Bryce (1961), The Making of the Good Neighbor Policy, Nueva York: Columbia University Press. 